\title{
Cold homes are associated with poor biomarkers and less blood pressure check-up: English Longitudinal Study of Ageing, 2012-2013
}

\author{
Ivy Shiue ${ }^{1,2}$
}

Received: 17 September 2015 / Accepted: 1 February 2016 / Published online: 13 February 2016

(C) The Author(s) 2016. This article is published with open access at Springerlink.com

\begin{abstract}
It has been known that outdoor temperature influences seasonal fluctuation of blood pressure and cholesterol levels, but the role of indoor temperature has been less studied. Therefore, the aim of the present study was to examine the associations between indoor temperature and biomarkers in a countrywide and population-based setting. Data was retrieved from the English Longitudinal Study of Ageing, 2012-2013. Information on demographics, room temperature and a series of biomarkers measured in the blood and lung was obtained at household interviews. $t$ test, chi-square test and a generalized linear model were performed cross-sectionally. Of 7997 older adults with the valid indoor temperature measurements, there were 1301 (16.3\%) people who resided in cold homes $\left(<18{ }^{\circ} \mathrm{C}\right)$. Age was inversely associated with people who resided in cold homes or who tended not to have blood pressure check-up. Those who resided in cold homes had higher blood pressure readings, worse handgrip, lower vitamin D levels, higher cholesterol levels, higher insulin-like growth factor levels, higher haemoglobin levels, lower level of white blood cell count and worse lung conditions. One in six older adults aged 50 and above in
\end{abstract}

$\underline{\text { Responsible editor: Philippe Garrigues }}$

Ivy Shiue

ivy.shiue@northumbria.ac.uk

1 Faculty of Health and Life Sciences, Northumbria University, Newcastle upon Tyne, NE1 8ST, England, UK

2 Alzheimer Scotland Dementia Research Centre, University of Edinburgh, Edinburgh, Scotland, UK
England resided in cold homes and had poor biomarker values. For the future research direction, studies with a longitudinal approach to systematically monitor indoor temperature, biomarkers and health and wellbeing would be suggested. From the practice and policy perspectives, increasing health knowledge on the adverse effect of low indoor temperature on risks of cardiac and respiratory conditions, affording to the heating and re-designing of residential buildings to keep warm by using efficient energy, should be kept as priority.

Keywords Adult health · Biomarker · Room temperature · Indoor environment $\cdot$ Cold home

\section{Introduction}

\section{Evidence before this study}

Cardiovascular disease has been persisting as the leading cause of illnesses and deaths globally (GBD 2013 Mortality and Causes of Death Collaborators 2015). With climate change, some regions could suffer from heat while some others might suffer from chill (Clearfield et al. 2014). There have also been observations on more hospital admissions on cold days than on warm days (Shiue et al. 2015, 2014a, b). Raised blood pressure (BP) and increased blood viscosity, as major risk contributors for cardiovascular disease, in moderate cold may be important causal factors in the increased winter morbidity and mortality due to heart attacks, strokes, respiratory symptoms, etc. (Collins 1986; Shiue and Shiue 2014). Apart from outdoor temperature, the indoor environment has gained attention for its effect on human health since we humans might spend much time indoors. 


\section{Knowledge gap}

It has been known that outdoor temperature influences the seasonal fluctuation of BP and cholesterol levels (Giaconi et al. 1989; Halonen et al. 2011). A recent pilot study of 26 older adults aged 70 and above has observed some change in physical performance in the circumstances of 20 and $30{ }^{\circ} \mathrm{C}$ (Stotz et al. 2014). However, the role of room temperature in biomarkers that could indicate many medical conditions has been much less studied.

\section{Study aim}

Following this context, therefore, the aim of the present study was to investigate the prevalence of low indoor temperature $\left(<18{ }^{\circ} \mathrm{C}\right)$ and to examine the associations between a cold home (low indoor temperature) and a series of biomarkers measured in the blood and lung in a countrywide and population-based setting with a focus on older adults since they could be more vulnerable than people in younger age groups.

\section{Methods}

\section{Study sample}

The English Longitudinal Study of Ageing (more details via http://www.elsa-project.ac.uk/) has been a countrywide, population-based, multi-year study since 1998. It is based on a representative sample of older adults aged 50+ living in private households in England, UK. A random sample was selected from the Health Survey for England (more details via http://www.hscic.gov.uk/healthsurveyengland) in different years. Data was collected continuously throughout the year (more details via http://www.esds.ac.uk/doc/5050/ $\mathrm{mrdoc} / \mathrm{pdf} / 5050$ _Wave_3_Technical_Report.pdf\#page=11). In the current analysis, the most recent study cohort, wave 6 in 2012-2013, with available data on demographics and objectively measured biomarkers and room temperature in older adults that was obtained by nurse interview was included.

\section{Variables and analyses}

Study exposure variable ( $x$ variable) was room temperature measured on the day of interview. It was measured in the room at the time BP was being taken. Figure 1 shows the distribution of room temperature from each household in the present study. Cold homes were defined as a room temperature below $18^{\circ} \mathrm{C}$, as recommended by the World Health Organization (more details via http://whqlibdoc.who.int/euro/pre-wholis/ ICP_BSM_002\%283\%29.pdf). Study outcome variables

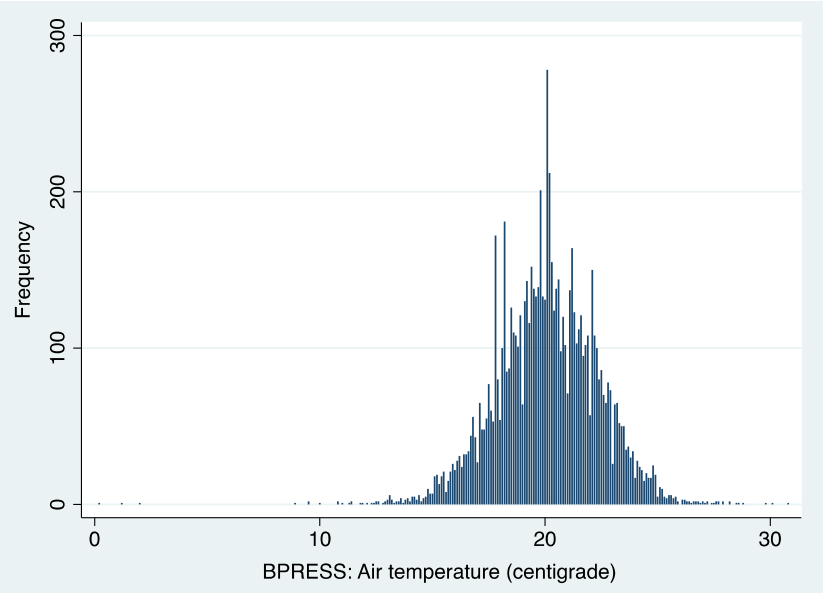

Fig. 1 Distribution of room temperature in the studied households

( $y$ variables) were a series of biomarkers that were measured in the blood and lung. Differences were examined by using $t$ test or chi-square test while associations were examined by using a generalized linear model, with $P<0.05$ considered statistically significant. Spike and scatter plots were also produced where needed. The statistical software STATA version 13.0 (STATA, College Station, Texas, USA; more details via http:// www.stata.com/) was used to perform all the analyses.

\section{Results}

Of 10,379 older adults aged 50 and above and included in the nurse interview data set, 7997 were with valid indoor temperature measurements. There were 1301 (16.3\%) people who resided in cold homes $\left(<18^{\circ} \mathrm{C}\right)$. Table 1 shows the differences and associations between cold homes and values of biomarkers measured in the blood and lung. Age was inversely associated with people who resided in cold homes or who tended not to have blood pressure check-up. Those who resided in cold homes had higher blood pressure readings, worse handgrip (of note: women tend to have lower grip strength than men have), lower vitamin D levels, higher cholesterol levels, higher insulin-like growth factor levels, higher haemoglobin levels, lower level of white blood cell count and worse lung conditions. The values in these biomarkers also showed linear associations with room temperature. However, there were no differences across sex, height and weight.

\section{Discussion}

In the present study, poor biomarkers that were associated with low indoor temperature were blood pressure, mean atrial pressure, handgrip, blood low-density lipoprotein level, vitamin D level, blood insulin-like growth factor, blood haemoglobin level, white blood cell count and lung function 
Table 1 Associations between cold homes and biomarkers

\begin{tabular}{|c|c|c|c|c|}
\hline & $\geq 18^{\circ} \mathrm{C}(n=6696,83.7 \%)$ & $<18{ }^{\circ} \mathrm{C}(n=1301,16.3 \%)$ & $P$ value & Beta $(95 \% \mathrm{CI})$ \\
\hline Sex & & & 0.922 & \\
\hline Male & $3001(83.7 \%)$ & $585(16.3 \%)$ & & \\
\hline Female & $3695(83.8 \%)$ & $716(16.2 \%)$ & & \\
\hline Age & & & $<0.001$ & \\
\hline $50-64$ & $2440(80.9 \%)$ & $575(19.1 \%)$ & & \\
\hline $65-79$ & $3249(83.9 \%)$ & $622(16.1 \%)$ & & \\
\hline $80+$ & $1007(90.6 \%)$ & $104(9.4 \%)$ & & \\
\hline Blood pressure check in the last year & & & $<0.001$ & \\
\hline Yes & $5586(84.6 \%)$ & $1016(15.4 \%)$ & & \\
\hline No & $1096(79.5 \%)$ & $283(20.5 \%)$ & & \\
\hline Dominant hand & & & 0.104 & \\
\hline Right-handed & $5887(83.3 \%)$ & $1180(16.7 \%)$ & & \\
\hline Left-handed & $654(85.6 \%)$ & $110(14.4 \%)$ & & \\
\hline Height (cm) & $165.3 \pm 11.4$ & $165.5 \pm 14.0$ & 0.504 & - \\
\hline Weight (kg) & $77.5 \pm 17.2$ & $77.7 \pm 17.8$ & 0.607 & - \\
\hline Waist (cm) & $95.3 \pm 28.8$ & $95.4 \pm 31.5$ & 0.904 & - \\
\hline Systolic (mmHg) & $133.7 \pm 18.7$ & $136.8 \pm 19.4$ & $<0.001$ & $-0.67(-0.85$ to -0.48$)$ \\
\hline Diastolic (mmHg) & $74.2 \pm 11.4$ & $76.8 \pm 11.0$ & $<0.001$ & $-0.61(-0.72$ to -0.50$)$ \\
\hline Pulse reading (bpm) & $66.9 \pm 19.6$ & $67.3 \pm 10.9$ & 0.423 & - \\
\hline Mean arterial pressure $(\mathrm{mmHg})$ & $94.0 \pm 12.2$ & $96.8 \pm 12.1$ & $<0.001$ & $-0.64(-0.75$ to -0.52$)$ \\
\hline Dominant hand grip $(\mathrm{kg})(n=7740)$ & $27.9 \pm 11.1$ & $29.2 \pm 11.3$ & $<0.001$ & $-0.31(-0.42$ to -0.21$)$ \\
\hline Non-dominant hand grip $(\mathrm{kg})(n=7740)$ & $25.4 \pm 10.5$ & $26.5 \pm 10.2$ & 0.001 & $-0.29(-0.39$ to -0.18$)$ \\
\hline Total blood cholesterol level (mmol/l) $(n=6085)$ & $5.5 \pm 1.2$ & $5.6 \pm 1.1$ & 0.011 & $-0.02(-0.04$ to -0.01$)$ \\
\hline Blood high-density lipoprotein level $(\mathrm{mmol} / \mathrm{l})(n=6082)$ & $1.7 \pm 0.5$ & $1.7 \pm 0.5$ & 0.328 & - \\
\hline Blood triglyceride level $(\mathrm{mmol} / \mathrm{l})(n=6085)$ & $1.5 \pm 0.9$ & $1.5 \pm 0.8$ & 0.082 & - \\
\hline Blood low-density lipoprotein level $(\mathrm{mmol} / \mathrm{l})(n=6015)$ & $3.2 \pm 1.0$ & $3.3 \pm 1.0$ & 0.002 & $-0.03(-0.04$ to -0.01$)$ \\
\hline Blood ferritin level $(\mathrm{ng} / \mathrm{ml})(n=6085)$ & $153.1 \pm 144.8$ & $151.0 \pm 153.4$ & 0.689 & - \\
\hline Blood C-reactive protein level (mg/l) $(n=6085)$ & $3.5 \pm 9.7$ & $3.3 \pm 6.1$ & 0.500 & - \\
\hline Vitamin D level (unit) $(n=6071)$ & $49.6 \pm 23.7$ & $44.1 \pm 21.8$ & $<0.001$ & $0.98(0.72-1-23)$ \\
\hline Blood insulin-like growth factor level $(\mathrm{nmol} / \mathrm{l})(n=6073)$ & $16.3 \pm 5.3$ & $16.8 \pm 5.5$ & 0.007 & $-0.10(-0.15$ to -0.04$)$ \\
\hline Blood-glycated haemoglobin level (\%) $(n=6011)$ & $41.2 \pm 8.6$ & $40.9 \pm 7.6$ & 0.285 & - \\
\hline Blood glucose level (mmol/1)—fasting samples only $(n=3226)$ & $5.4 \pm 1.0$ & $5.4 \pm 0.8$ & 0.857 & - \\
\hline Blood fibrinogen level $(\mathrm{g} / \mathrm{l})(n=5967)$ & $3.0 \pm 0.5$ & $3.0 \pm 0.5$ & 0.446 & - \\
\hline Blood haemoglobin level $(\mathrm{g} / \mathrm{dl})(n=6019)$ & $13.7 \pm 1.3$ & $13.9 \pm 1.3$ & 0.001 & $-0.05(-0.07$ to -0.04$)$ \\
\hline Blood mean corpuscular haemoglobin level (pg/cell) $(n=6019)$ & $30.0 \pm 1.8$ & $30.1 \pm 1.7$ & 0.172 & - \\
\hline White blood cell count $\left(\times 10^{9}\right.$ cells $\left./ 1\right)(n=6019)$ & $6.5 \pm 2.0$ & $6.4 \pm 1.9$ & 0.005 & $0.08(0.06-0.11)$ \\
\hline Lung: forced vital capacity $(n=7009)$ & $3.3 \pm 1.1$ & $3.4 \pm 1.1$ & $<0.001$ & $-0.04(-0.05$ to -0.03$)$ \\
\hline Lung: forced expiratory flow $(n=7009)$ & $2.4 \pm 0.8$ & $2.5 \pm 0.8$ & 0.0001 & $-0.03(-0.04$ to -0.02$)$ \\
\hline Lung: peak expiratory flow $(n=7009)$ & $6.5 \pm 2.4$ & $6.7 \pm 2.3$ & 0.004 & $-0.06(-0.09$ to -0.04$)$ \\
\hline
\end{tabular}

values. Below is the existing literature, although very much limited, to compare with.

\section{Low temperature and health}

Previously, it was observed that a low temperature could change cerebral blood volume and centre-of-foot pressure during walking in young adults (Demura et al. 2008), although the study sample was rather small $(n=18)$. While the handgrip of young and healthy college students $(n=12)$ was not significantly influenced by a low temperature at $18{ }^{\circ} \mathrm{C}$ (Barter and Freer 1984), older adults in the present study were affected; when room temperature dropped below $18{ }^{\circ} \mathrm{C}$. Again, low temperature might not affect lung function in healthy young adults $(n=22)$, but it did affect older adults in the present study that is consistent with a previous study (Evans et al. 2005). For other biomarkers that were associated with the low indoor temperature among 
older adults in the present study, there was no other literature that could be compared and discussed.

On the other hand, temperature could profoundly influence growth of heterothermic vertebrates. This was previously observed in fish where temperature-induced variation in growth was associated with differences in systemic insulin-like growth factor I and local (i.e. muscle) insulin-like growth factor I mRNA levels (Luckenbach et al. 2007). Using human sample in the present study, the similar finding of blood insulin-like growth factor was also influenced by the low indoor temperature.

\section{Strengths and limitations}

The present study has a few strengths. Firstly, it lies in its very large and representative study sample (countrywide and population-based) and in recent years. Secondly, it is also the first time to analyse the associations between room temperature and a series of biomarkers measured in the blood and lung in England, UK. However, there are also a few limitations that cannot be ignored. First, the room temperature was measured once in the room when biomarkers were being measured. Around the housing in other rooms, the temperature might be different. Second, the causality cannot be established due to the cross-sectional study design in nature. Therefore, the results could only reflect the situation at interview but not necessarily the whole time. Taken together, future studies keeping the strengths and overcoming the limitations mentioned above with a longitudinal approach to systematically monitor indoor temperature, biomarkers and health and wellbeing would be recommended.

\section{Future directions for research, practice and policy}

One in six older adults aged 50 and above in England resided in cold homes, less had blood pressure check-up and were with poor biomarker values including blood pressure, mean atrial pressure, handgrip, blood low-density lipoprotein level, vitamin D level, blood insulin-like growth factor, blood haemoglobin level, white blood cell count and lung function. For the future research direction, studies with a longitudinal or experimental approach to systematically monitor indoor temperature, biomarkers and health and wellbeing in the whole population would be suggested. For clinical practice, maintaining indoor temperature at $18{ }^{\circ} \mathrm{C}$ or above should be implemented across all seasons throughout the year to optimize human health and wellbeing. In addition, intensive room heating that could decrease morning BP surge in winter and consequently hospital admissions due to cardiovascular and/or respiratory conditions would need to be designed via the heating technology (Saeki et al. 2013; Hashiguchi et al. 2004). Increasing health knowledge on the adverse effect of low indoor temperature on the higher risks of cardiac and respiratory conditions and assisting with job security in order to afford the heating and re-designing of residential buildings with more energy saving to keep the indoor efficiently warm should also be kept as a health priority. Since it was also observed that older adults in England who resided in cold homes below $18{ }^{\circ} \mathrm{C}$ had a lower level of vitamin $\mathrm{D}$ in the present study, encouraging people to spend more time in the sun while designing homes that could retain sunshine for longer time periods could be considered as well. These aspects would therefore need policymakers, clinicians, nursing staff, community workers, architects, urban planners and civil engineers to work together in order to protect the public's health and to maintain wellbeing and quality of life when facing the extended life expectancy in the coming decades.

Acknowledgments None.

\section{Compliance with ethical standards}

Conflict of interest The author declares that he/she has no competing interests.

Ethics approval Since there is only secondary data analyses employed without any participant personal information identified by extracting statistical data from the UK Data Archive website, no further ethics approval for conducting the present study is required (more details via http://www. ethicsguidebook.ac.uk/Secondary-analysis-106).

Open Access This article is distributed under the terms of the Creative Commons Attribution 4.0 International License (http:// creativecommons.org/licenses/by/4.0/), which permits unrestricted use, distribution, and reproduction in any medium, provided you give appropriate credit to the original author(s) and the source, provide a link to the Creative Commons license, and indicate if changes were made.

\section{References}

Barter TJ, Freer PC (1984) Effect of temperature on handgrip holding time. Br J Sports Med 18:91-95

Clearfield M, Pearce M, Nibbe Y, Crotty D, Wagner A (2014) The "New Deadly Quartet" for cardiovascular disease in the 21 st century: obesity, metabolic syndrome, inflammation and climate change: how does statin therapy fit into this equation? Curr Atheroscler Rep 16(1):380

Collins KJ (1986) Low indoor temperatures and morbidity in the elderly. Age Ageing 15:212-220

Demura S, Yamaji S, Kitabashi T, Yamada T, Uchiyama M (2008) Effects of room temperature and body position change on cerebral blood volume and center-of-foot pressure in healthy young adults. J Physiol Anthropol 27:63-70

Evans TM, Rundell KW, Beck KC, Levine AM, Baumann JM (2005) Airway narrowing measured by spirometry and impulse oscillometry following room temperature and cold temperature exercise. Chest 128:2412-2419 
GBD 2013 Mortality and Causes of Death Collaborators (2015) Global, regional, and national age-sex specific all-cause and cause-specific mortality for 240 causes of death, 1990-2013: a systematic analysis for the Global Burden of Disease Study 2013. Lancet 385(9963): $117-71$

Giaconi S, Ghione S, Palombo C, Genovesi-Ebert A, Marabotti C, Fommei E, Donato L (1989) Seasonal influences on blood pressure in high normal to mild hypertensive range. Hypertension 14:22-27

Halonen JI, Zanobetti A, Sparrow D, Vokonas PS, Schwartz J (2011) Outdoor temperature is associated with serum HDL and LDL. Environ Res 111:281-287

Hashiguchi N, Tochihara Y, Ohnaka T, Tsuchida C, Otsuki T (2004) Physiological and subjective responses in the elderly when using floor heating and air conditioning systems. J Physiol Anthropol Appl Human Sci 23:205-213

Luckenbach JA, Murashige R, Daniels HV, Godwin J, Borski RJ (2007) Temperature affects insulin-like growth factor I and growth of juvenile southern flounder, Paralichthys lethostigma. Comp Biochem Physiol A Mol Integr Physiol 146:95-104

Saeki K, Obayashi K, Iwamoto J, Tanaka Y, Tanaka N, Takata S, Kubo H, Okamoto N, Tomioka K, Nezu S, Kurumatani N (2013) Influence of room heating on ambulatory blood pressure in winter: a randomised controlled study. J Epidemiol Community Health 67:484-490

Shiue I, Shiue M (2014) Indoor temperature below $18^{\circ} \mathrm{C}$ accounts for $9 \%$ population attributable risk for high blood pressure in Scotland. Int J Cardiol 171:e1-2

Shiue I, Perkins DR, Bearman N. Hospital admissions of hypertension, angina, myocardial infarction and ischemic heart disease peaked at physiologically equivalent temperature $0{ }^{\circ} \mathrm{C}$ in Germany in 2009 2011. Environ Sci Pollut Res Int. 2015 Aug 20. doi:10.1007/ s11356-015-5224-X

Shiue I, Perkins DR, Bearman N (2014a) Pulmonary heart disease but not pulmonary embolism admissions peaked at physiologically equivalent temperature $0^{\circ} \mathrm{C}$ in Germany in 2009-2011. Int J Cardiol 177(2):584-5

Shiue I, Perkins DR, Bearman N (2014b) Valve disease and hypotension hospital admissions peaked at physiologically equivalent temperature $0-5^{\circ} \mathrm{C}$ in Germany in 2009-2011. Int J Cardiol 177(1):169-70

Stotz A, Rapp K, Oksa J, Skelton DA, Beyer N, Klenk J, Becker C, Lindemann U (2014) Effect of a brief heat exposure on blood pressure and physical performance of older women living in the community - a pilot-study. Int J Environ Res Public Health 11(12): $12623-31$ 